\title{
OTIMIZAÇÃO DO ITINERÁRIO DE ESCÓRIA: REDUÇÃO DE CUSTOS E IMPACTOS AMBIENTAIS*
}

Gustavo Ribeiro de Carvalho ${ }^{1}$

\section{Resumo}

O presente trabalho apresenta o projeto que propiciou melhores formas de controles internos possibilitando a redução do itinerário utilizado para o transporte de escória entre os Altos Fornos da Usina Presidente Vargas - UPV e a CSN Cimentos através da implantação de sistemas de controles de viagens por Validadores de Acesso, com a finalidade de viabilizar a utilização da melhor rota correspondente à menor distância entre as unidades operacionais e por consequência menor custo e impactos ambientais. A otimização do trajeto de escória possibilitou sinergia entre economia, meio ambiente e sociedade proporcionando ganhos financeiros e de produtividade. $O$ projeto trouxe melhorias significativas, refletidas nos principais aspectos: Benefício financeiro com a redução dos custos contratuais com transporte interno de Escória; Inovação tecnológica que possibilitou controlar o registro de viagens por caminhão para melhor apuração da quantidade de viagens e maior confiabilidade dos desvios de estoques; Aumento da produtividade através da otimização do trajeto e aumento na performance de abastecimento da Cimentos; Redução mensal de $18 \mathrm{tCO}_{2}$ eq. de gases do efeito estufa associado a economia média de 6600 litros do aspecto ambiental "consumo de recursos naturais" (Óleo diesel) com a otimização de 13.000 $\mathrm{km}$.

Palavras-chave: Otimização de itinerário; Inovação Tecnológica; Redução de Custos; Impacto Ambiental

\section{OTIMIZATION OF SLAG ITINERARY: COST REDUCTION AND ENVIRONMENTAL IMPACTS}

\begin{abstract}
This paper presents a project that provided the best forms of internal control, enabling a reduction of the itinerary used for slag transport between the UPV's Blast Furnaces and CSN Cement Plant, through the implementation of trip control system using Access Validators, with the goal of enabling the use of the best matching route to the shortest distance between the operating units and therefore the lowest cost and environmental impact. The optimization of slag path has enabled synergy between economy, environment and society, providing financial and productivity gains. The project brought significant improvements, reflected in key aspects: Economic benefit, by reducing contractor costs with internal slag transport; Technological innovation, that enabled the control of the truck's travel record and to better calculate the amount of trips and increased reliability of inventory variances; Increased productivity, by optimizing the path and increase in the supply performance of the Cement Plant; Monthly reduction of $18 \mathrm{tCO} 2$ eq. of greenhouse gases associated with average savings of 6600 liters of "consumption of natural resources" (diesel oil) environmental aspect with optimization of $13,000 \mathrm{~km}$.
\end{abstract}

Keywords: Path Otimization; Technological Inovation; Cost Reduction; Environmental Impact

1 Engenheiro Ambiental, Especialista em Meio Ambiente, GGMB/GOAR, Companhia Siderúrgica Nacional, Volta Redonda, Rio de Janeiro, Brasil. 


\section{INTRODUÇÃO}

As organizações no atual cenário global buscam otimizar e melhorar seus processos, reduzir desperdícios e aumentar sua performance operacional, estes são fatores essenciais para sua sobrevivência e competividade no mercado. Para alcançar estes objetivos é vital o auxílio e implantação de novas tecnologias que controlem racionalmente os custos envolvidos nos processos e agreguem valor aos produtos.

A unidade da CSN Cimentos em Volta Redonda construída no interior da Usina Presidente Vargas - UPV, iniciou suas operações de fabricação de cimento em Agosto de 2010 , com capacidade nominal de 2,4 milhões de toneladas/ano. O cimento é produzido utilizando-se como principal matéria-prima a escória do processo siderúrgico dos Altos Fornos da Usina Presidente Vargas.

O objetivo desse trabalho é a redução de custos no itinerário utilizado para o transporte de escória entre os Altos Fornos 02 \& 03 e a unidade de Cimentos, através da implantação de sistemas de controle de viagens via Validadores de Acessos com a finalidade de determinar o roteiro ótimo a ser realizado, que corresponda ao caminho de menor distância entre as unidades operacionais e por consequência menor custo e impactos ambientais, contribuindo para o atendimento a Política de Meio Ambiente e requisitos legais (Normas/Leis).

\section{MATERIAIS E MÉTODOS}

A unidade da CSN Cimentos iniciou a produção de cimento com uma grande vantagem competitiva: a sinergia da operação é garantida com a utilização no seu processo produtivo como matéria-prima às 5.000 toneladas de escória produzidas diariamente em média nos altos fornos durante o processo de fabricação do ferro gusa (matéria-prima do aço) na Usina Presidente Vargas, em Volta Redonda (RJ). A Figura 1 mostra a sinergia entre os processos produtivos, destacando o transporte de escória entre as unidades que é o objeto de estudo desse trabalho.

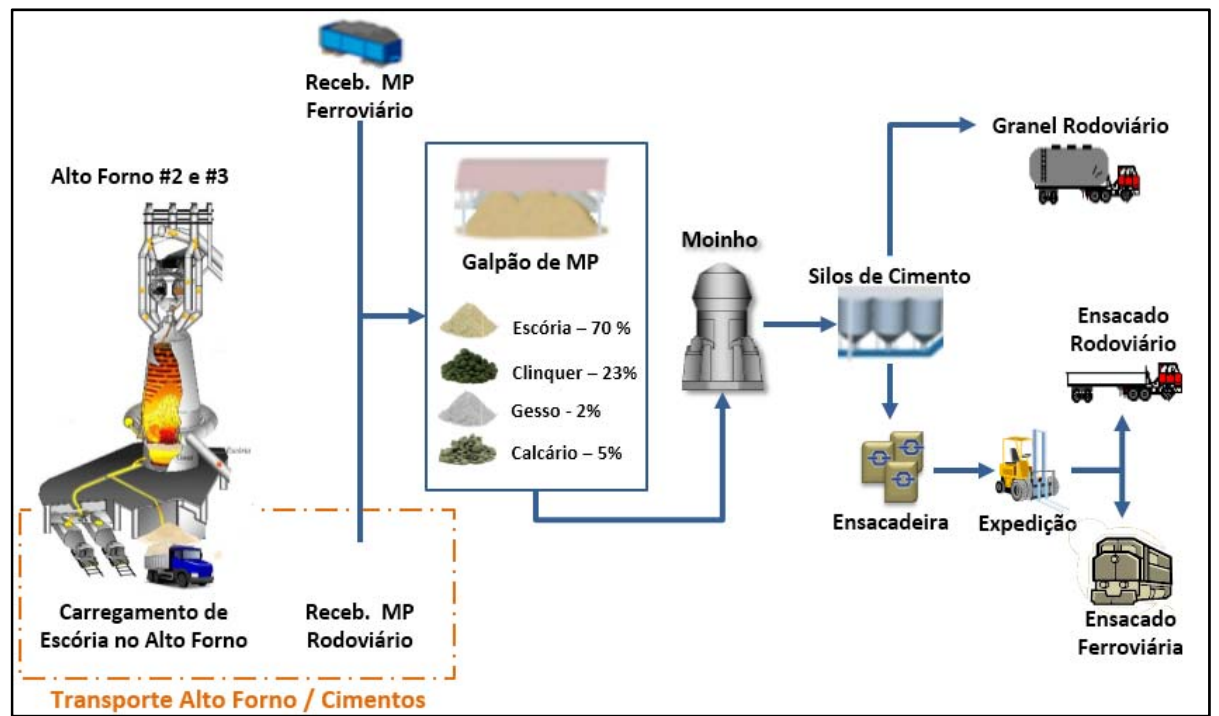

Figura 1. Fluxograma do processo de movimentação-suprimento de escória para a Fábrica de Cimento 


\subsection{Itinerário do Transporte de Escória}

Para garantir o escoamento da escória gerada nos Altos Fornos para utilização como matéria-prima na CSN Cimentos, foi contratada uma empresa terceirizada para o transporte rodoviário através de caminhões com capacidade média de 17 toneladas, percorrendo interruptamente os $3,75 \mathrm{~km}$ entre as duas unidades devido a produção contínua dos processos.

O controle e a quantidade de viagens são realizados na balança no interior da Usina, onde todos os caminhões após serem carregados no Alto Forno devem direcionar para esse setor para recebimento do ticket de carregamento e pesagem por amostragem. Essa amostragem é realizada pelos funcionários da CSN na balança, seguindo o critério estabelecido pela CSN de $10 \%$ dos caminhões carregados. A Figura 2 mostra todo trajeto percorrido pelos caminhões entre o carregamento e descarregamento da escória.

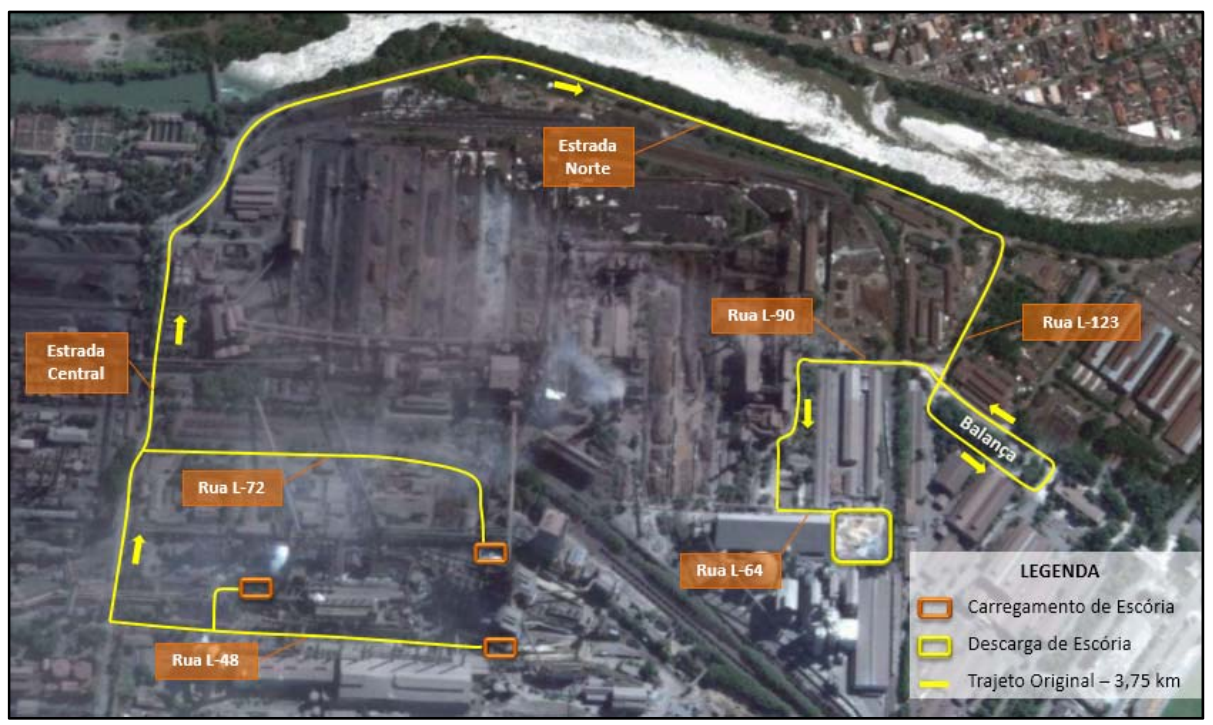

Figura 2. Itinerário do Transporte de Escória

\subsection{Otimização do Itinerário de Escória}

A fim de que houvesse um melhor estudo sobre os itinerários em relação aos tempos praticados para a entrega de escória na unidade Cimentos, foram coletados e analisados dados da Planta Geral da UPV, registro de cargas e informações sobre geração e consumo (PVP) das duas unidades que possibilitaram obter informações referentes a possíveis percursos a serem utilizados para atender ao escoamento de escória entre os Altos Fornos e a CSN Cimentos.

Com estas informações mapeadas, foi possível gerar dados como distância, tempo e consumo médio de combustível para o deslocamento entre um ponto e outro, que são extremamente importantes para determinar itinerários otimizados, reduções de custos e consequentemente os ganhos ambientais.

A partir dessas informações foi possível identificar o trajeto ótimo para otimizar o itinerário do transporte de escória com a redução de 1,8 quilômetros por viagem, mas com uma ressalva quanto a pesagem dos caminhões e principalmente a validação das viagens realizadas pela empresa contratada. 

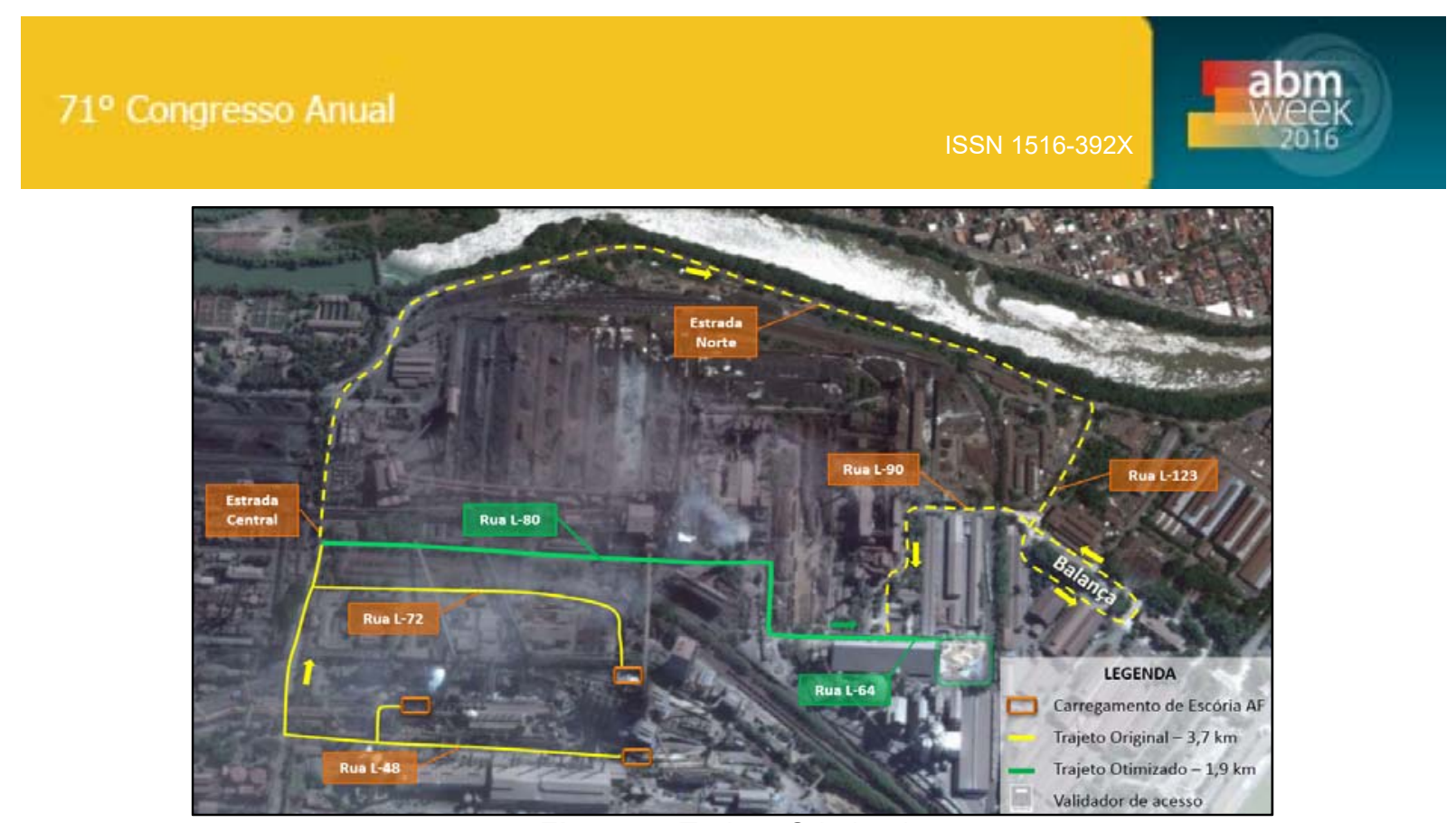

\subsection{Validadores de Acesso}

Figura 3. Trajeto Otimizado

Para viabilizar a utilização da melhor rota correspondente à menor distância entre as unidades operacionais, seria necessário a implantação de um sistema de controle automatizado para seleção dos caminhões que serão amostrados para pesagem na balança e validar o restante das viagens pelo trajeto otimizado.

Para implantação desse projeto a equipe técnica optou pelo desenvolvimento interno de sistema de baixo custo e que atendesse todas as exigências de pesagem e controle das viagens, garantindo a rastreabilidade e maior confiabilidade dos desvios de estoques. Esse projeto foi nomeado como Validador de Acesso.

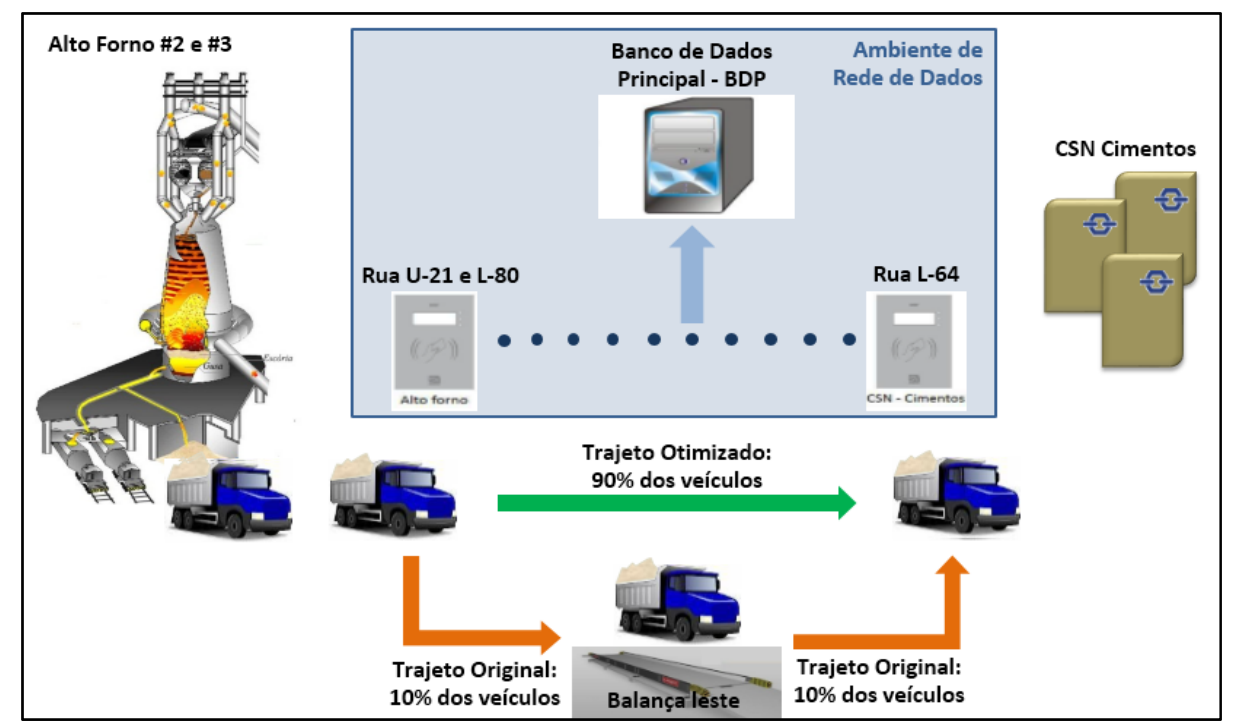

Figura 4. Funcionamento do Validador de Acesso

A tecnologia desenvolvida dos Validadores de Acesso é similar aos registradores de jornada de trabalho, com capacidade para emitir documentos fiscais e realizar controles de natureza fiscal, referentes ao carregamento e descarregamento dos caminhões utilizados no transporte de escória.

Outra tecnologia desenvolvida neste sistema para a implantação do trajeto otimizado foi a seleção aleatória dos caminhões para pesagem, possibilitando a utilização do trajeto otimizados pelos caminhões que não necessitam passar pela balança para pesagem. 
A partir do desenvolvimento desse sistema os validadores foram instalados em pontos estratégicos que possibilitaram a utilização do trajeto otimizado e atendimento as exigências fiscais da CSN, conforme mostrado na Figura 5.

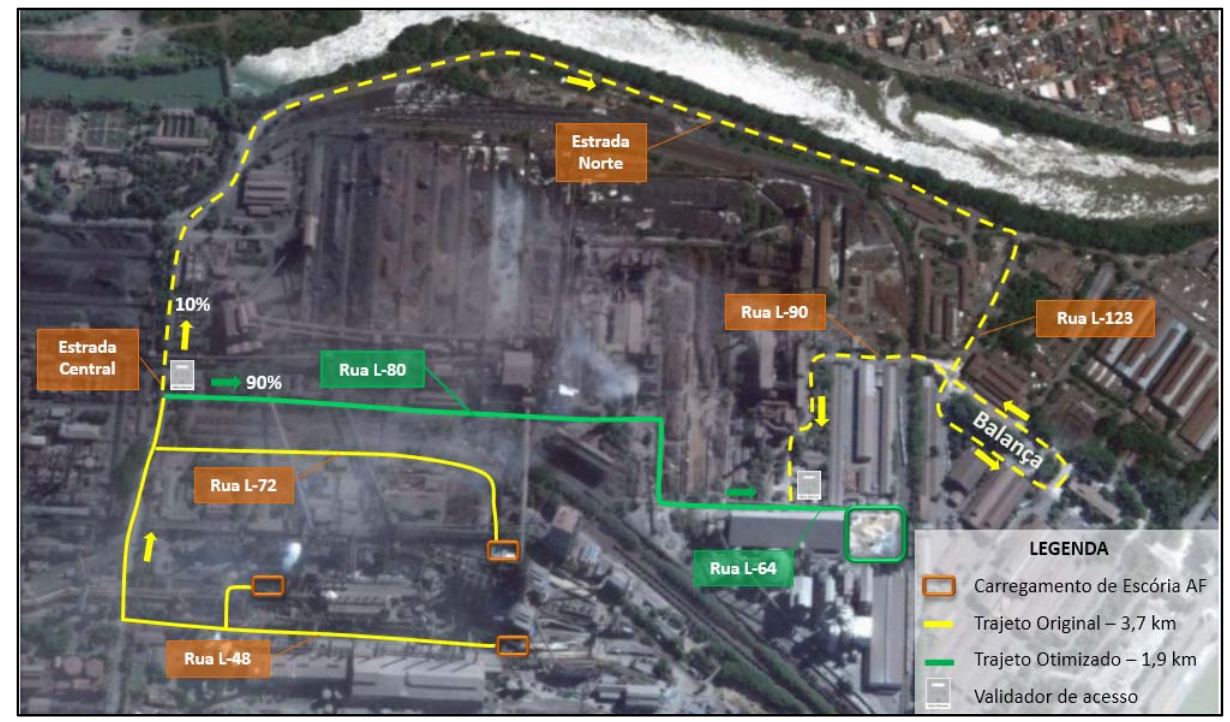

Figura 5. Localização dos Validadores de Acesso.

Após o carregamento nos três pontos mencionados na Figura 5, o caminhão deslocase para o Validador de Acesso instalado no ponto de interseção entre a Estrada Central e a Rua L-80 onde o motorista registra o carregamento do veículo. O sistema aleatoriamente seleciona a amostragem de $10 \%$ para pesagem na balança pelo percurso mais longo e o restante dos veículos são selecionados para o trajeto otimizado. Para concluir o ciclo do transporte de escória, após a pesagem ou não dos caminhões, os veículos são deslocados para o pátio de matérias-primas da CSN Cimentos onde após o descarregamento o motorista finaliza a viagem com o registro no Validador de Acesso, instalado próximo a saída do pátio.

\section{RESULTADOS E DISCUSSÃO}

A partir da implantação do sistema de Validadores de Acesso e utilização do trajeto otimizado, foi possível mensurar os ganhos quanto à distância do trajeto, tempo de viagem e velocidade do percurso conforme mostrado na Figura 6: 


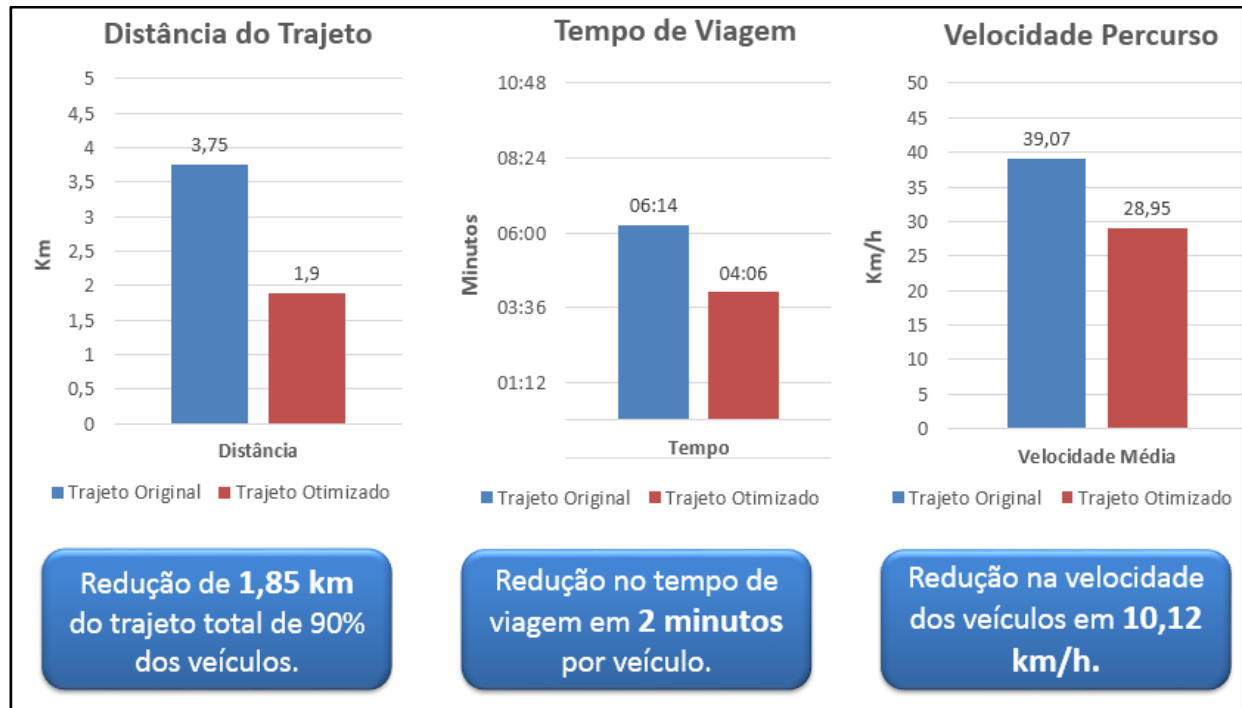

Figura 6. Ganhos por Viagem do Itinerário Otimizado.

Considerando que os caminhões utilizados no transporte da escoria entre o Alto Forno e a CSN Cimentos tem uma autonomia de $2 \mathrm{~km} /$ litro, a otimização do itinerário reduziu significativamente o consumo mensal de óleo diesel, conforme mostrado na Figura 7:

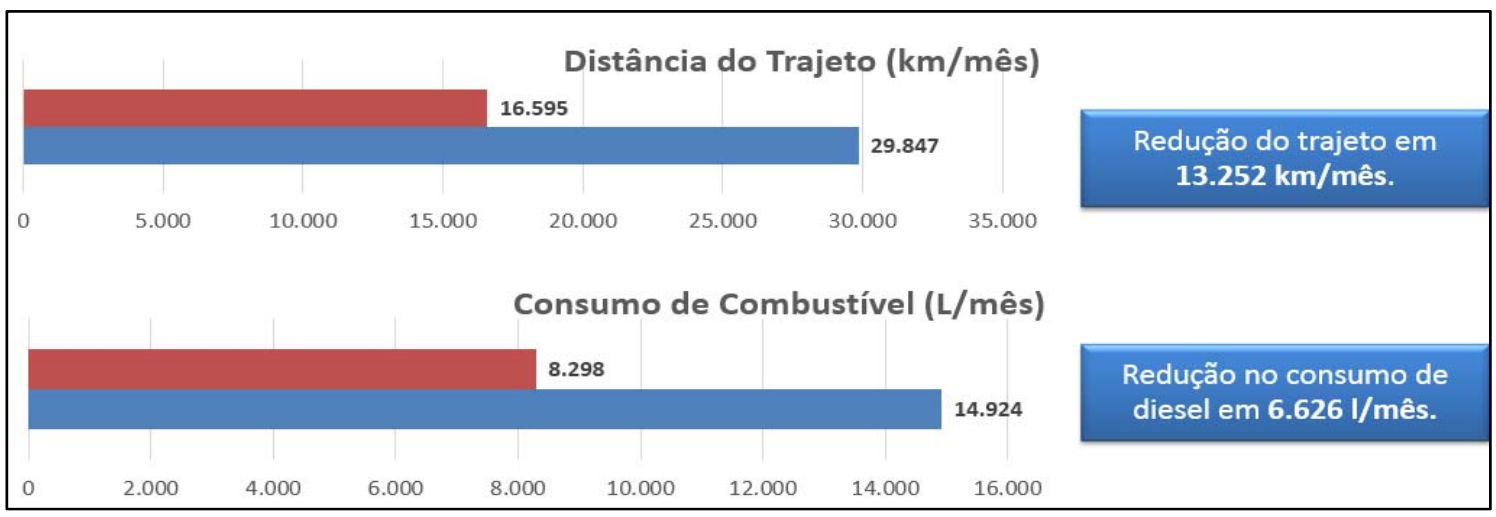

Figura 7. Economia de combustível com a adoção do novo itinerário

É importante destacar que anualmente serão economizados mais de 150 mil quilômetros com a otimização do itinerário, ou seja, quase quatro voltas na circunferência do planeta Terra que possuí 40 mil quilômetros.

Através da redução do trajeto e consequentemente a redução dos custos com combustível e manutenção da frota terceirizada responsável pelo transporte de escória, a CSN renegociou o contrato e obteve uma redução média de $21 \%$ no custo mensal, conforme Figura 8. 

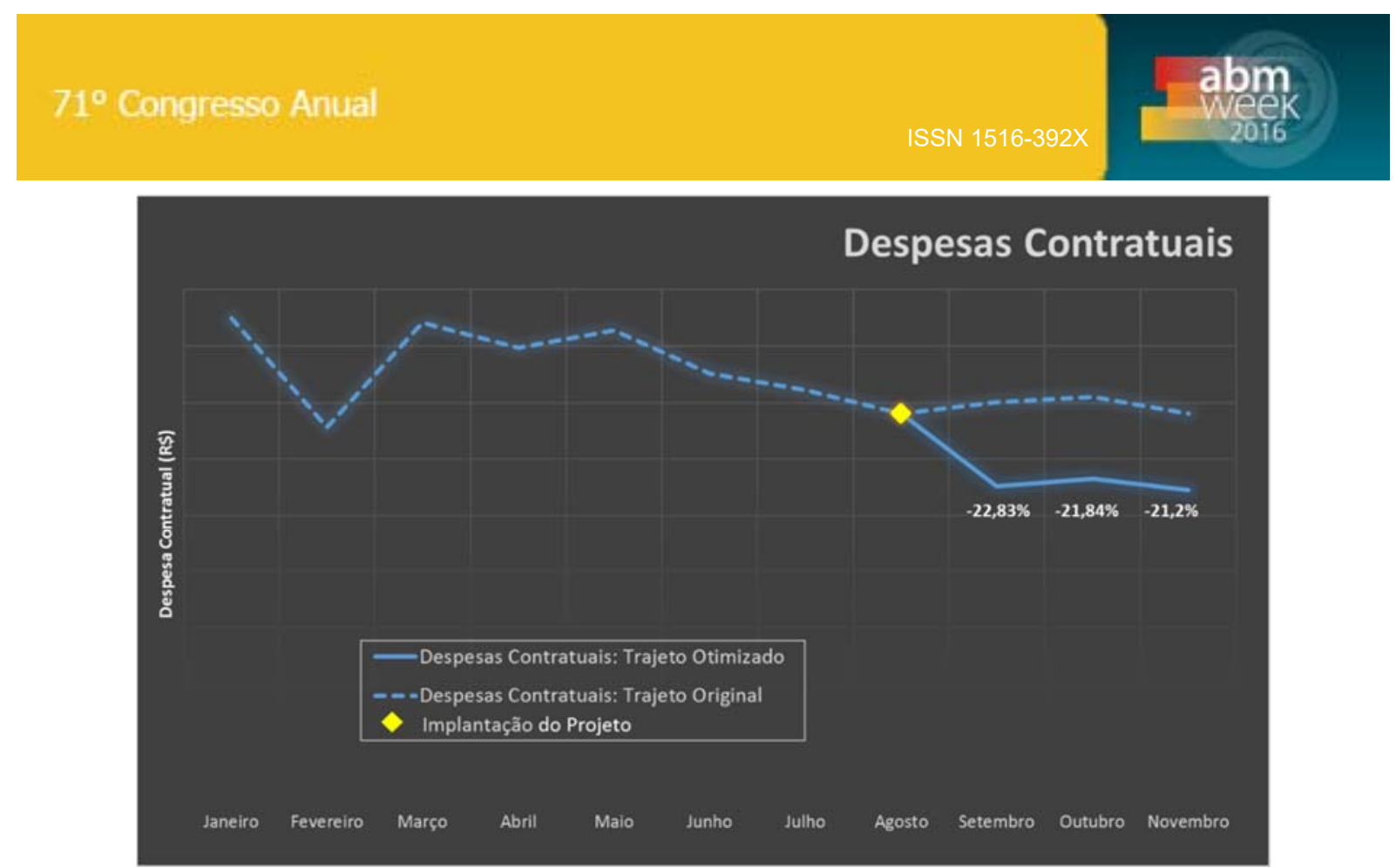

Figura 8. Despesas Contratuais.

O benefício financeiro é essencial para a competividade e sobrevivência da empresa, mas o principal benefício deste projeto foi a redução nas emissões dos Gases do Efeito Estufa (GEE) responsáveis pelo aquecimento global do planeta, através da redução no consumo de um recurso não-renovável (Óleo Diesel).

O cálculo das emissões de gases de efeito estufa (GEE) foi realizado com base na metodologia de contabilização do IPCC (Intergovernmental Panel on Climate Change) utilizada no Inventário de Emissões de Gases de Efeito Estuda da CSN, e os resultados são mostrados na Figura 9:

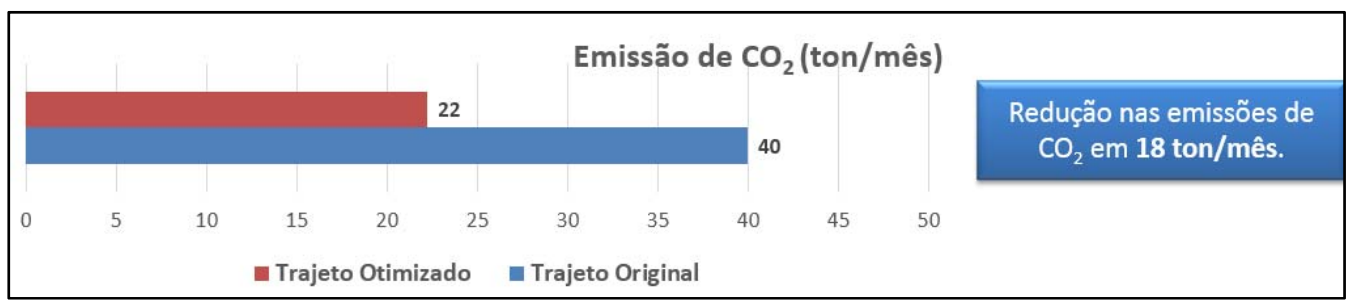

Figura 9. Emissão de Gases do Efeito Estufa

\section{CONCLUSÃO}

A otimização do trajeto de escória possibilitou sinergia entre economia, meio ambiente e sociedade proporcionando ganhos financeiros e de produtividade. O projeto trouxe melhorias significativas, refletidas nos principais aspectos:

$>$ Benefício financeiro com a redução dos custos contratuais com transporte interno de Escória,

$>$ Inovação tecnológica que possibilitou controlar o registro de viagens por caminhão para melhor apuração da quantidade de viagens e maior confiabilidade dos desvios de estoques;

$>$ Aumento da produtividade através da otimização de $45 \%$ do trajeto e aumento na performance de abastecimento da Cimentos.

$>$ Redução mensal de 18 tCO2 eq. de gases do efeito estufa associado a economia média de 6600 litros do aspecto ambiental "consumo de recursos naturais" (Óleo diesel) com a otimização de 13.000 km, contribuindo para a minimização do aquecimento global do planeta. 
Além dos pontos positivos mencionados acima, o desenvolvimento do projeto abriu novos precedentes de outros rotogramas, valorizando a capacidade técnica de seus colaboradores na busca de soluções para a empresa. Podemos concluir que o projeto atingiu as metas preconizadas na abertura dos estudos e ainda, passou a contribuir com a redução de custos com todos os benefícios ambientais associados.

\section{REFERÊNCIAS}

1 SU-60209 - Mapa Geral UPV (Estradas e Ruas)

2 IPCC - Intergovernmental Panel on Climate Change. 2006 IPCC Guidelines for National Greenhouse Gas Inventories. Japão, 2006.. 